\title{
Preparation of PtRu/C Electrocatalysts by Borohydride Reduction for Methanol Oxidation in Acidic and Alkaline Medium
}

\author{
Monique Carolina Lima dos Santos, Rita Maria Dutra, Vilmaria Aparecida Ribeiro, \\ Estevam Vitório Spinacé and Almir Oliveira Neto* \\ Instituto de Pesquisas Energéticas e Nucleares - IPEN/CNEN-SP, Av. Prof. Lineu Prestes, 2422 - \\ Cidade Universitária - CEP 05508-900 São Paulo, SP, Brazil \\ *E-mail: aolivei@ipen.br
}

doi: $10.20964 / 2017.05 .26$

Received: 5 January 2017 / Accepted: 11 March 2017 / Published: 12 April 2017

\begin{abstract}
$\mathrm{PtRu} / \mathrm{C}$ electrocatalysts were performed according to the borohydride reduction method and characterized by X-ray diffraction (XRD), energy dispersive analysis (EDX), transmission electron microscopy, cyclic voltammetry $(\mathrm{CV})$ and polarization curves in alkaline and acidic medium. The Xray diffraction (XRD) of $\mathrm{PtRu} / \mathrm{C}$ showed $\mathrm{Pt}$ peaks attributed to the face-centered cubic (fcc) structure and a shift in $\mathrm{Pt}(\mathrm{fcc})$ peaks indicated that $\mathrm{Ru}$ was incorporated into Pt lattice. TEM results showed mean particles sizes in the range of $2.0-4.0 \mathrm{~nm}$ for all electrocatalysts prepared: therefore, the borohydride reduction process was considered effective for the preparation of $\mathrm{PtRu} / \mathrm{C}$ electrocatalysts with a different atomic ratio. The activity for the methanol oxidation in acidic and alkaline media was investigated at room temperature, by cyclic voltammetry and chronoamperometry. Cyclic voltammetry and chronoamperometry studies showed that $\mathrm{PtRu} / \mathrm{C}$ (50:50) had superior performance for methanol oxidation, compared with other electrocatalysts prepared considering acidic and alkaline studies. The currents values observed for alkaline media were higher than those observed for acidic media. Polarization curves, also, showed PtRu/C (50:50) with superior performance for methanol oxidation, when compared with $\mathrm{Pt} / \mathrm{C}$, and this improvement of performance could be associated with the occurrence of the bifunctional mechanism and electronic effect.
\end{abstract}

Keywords: Borohydride reduction process, PtRu/C, methanol electro-oxidation, alkaline medium, acidic media, polarization curves

\section{$\underline{\text { FULL TEXT }}$}

(C) 2017 The Authors. Published by ESG (www.electrochemsci.org). This article is an open access article distributed under the terms and conditions of the Creative Commons Attribution license (http://creativecommons.org/licenses/by/4.0/). 